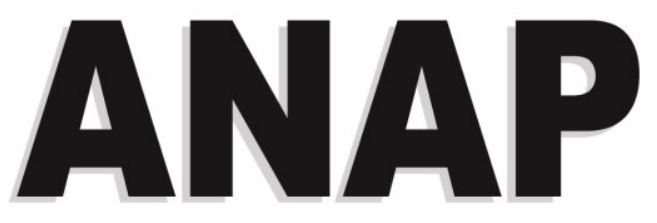

\title{
A situação atual da gestão dos resíduos sólidos na microrregião de Lavras, Estado de Minas Gerais, Brasil.
}

\author{
Situación actual de la gestión de residuos sólidos en la microregión de Lavras, Estado \\ de Minas Gerais, Brasil
}
The current situation of solid waste management in the microregion of Lavras, State of Minas Gerais, Brazil.

\begin{abstract}
Écio Souza Diniz
Universidade Federal de Viçosa, doutorando em Botânica. Viçosa, Minas Gerais, Brasil. eciodiniz@gmail.com (031) 3899-2651. Av. P.H Rolfs, s/n - Departamento de Biologia Vegetal, Laboratório de Ecologia e Evolução de Plantas, Campus Universitário, Viçosa, Minas Gerais, CEP 36570-900.
\end{abstract}

Luis Antônio Coimbra Borges

Universidade Federal de Lavras, professor pesquisador. Lavras, Minas Gerais, Brasil. luis.borges@dcf.ufla.br. (035) 3829-1428. Campus Universitário - Departamento de Ciências Florestais, Laboratório de Avaliação de Impacto e Gestão de Recursos Naturais e Legislação Ambiental, Caixa postal 3037, CEP 37200-000.

José Luiz Pereira

Universidade Federal de Lavras, professor pesquisador. Lavras, Minas Gerais, Brasil. jlprezen@dcf.ufla.br. (035) 3829-1428. Campus Universitário - Departamento de Ciências Florestais, Laboratório de Política e Legislação Ambiental, Caixa postal 3037,

Resumo - A gestão de resíduos é um setor do saneamento público que teve origem no período colonial. Atualmente, entretanto, o gerenciamento desses resíduos é uma questão complexa devido à elevada expansão urbana, a grande quantidade e diversidade de resíduos produzidos, recursos públicos limitados e limitações de energia e recursos naturais. O objetivo deste estudo foi verificar a atual situação da gestão de resíduos sólidos na microrregião de Lavras. Assim, o estudo foi conduzido por meio de dados obtidos através de idas aos municípios, consulta a informações oficiais de bancos de dados nacionais e estaduais como IBGE e Fundação Estadual do Meio Ambiente. Com base nesses dados, concluiu-se que na microrregião de Lavras a gestão integrada de resíduos sólidos ainda está em evolução, visto que maior parte de seus municípios ainda fazem destinação final irregular de seus resíduos sólidos em lixões, carecem no apoio a reciclagem e catadores e apresentam inconformidades com a Lei no 12.305 que outorga Política Nacional de Resíduos Sólidos. Uma atuação governamental mais incisiva através da exigência de cumprimento dos incisos presentes na Lei $n$ ㅇ 12.305 , juntamente com o maior investimento na criação de oficinas de conscientização da população pode auxiliar na evolução dos sistemas de gestão dos municípios da microrregião estudada.

Palavras-chave: Política nacional. Gerenciamento. Coleta seletiva. Conscientização.

Resumen- La gestión de residuos es un sector del saneamiento público que tuvo origen en el período colonial. Actualmente, por tanto, el manejo de esos residuos sólidos es una interrogante compleja debido a la elevada expansión urbana, la alta cantidad y diversidad de residuos producidos, recursos públicos limitados y limitaciones de energía y recursos naturales. El objetivo de este estudio fue evaluar la situación actual de la gestión de residuos sólidos en la microrregión de Lavras. De este modo, el estudio fue desarrollado a través de jornadas de campo en los municipios, consulta de información oficial en banco de datos nacionales y estadales como IBGE y Fundación 
Estadual de Medio Ambiente. Con base en esos datos, se concluye que en la microrregión de Lavras la gestión integrada de residuos sólidos todavía está en evolución, debido a que la mayor parte de sus municipios aún mantienen un destino final irregular de sus residuos sólidos en vertederos, carecen de apoyo al reciclaje y captadores y presentan inconformidades con la ley $n^{\circ} 12.305$ que otorga la Política Nacional de Residuos Sólidos. Una actuación gubernamental más incisiva a través de la exigencia del cumplimento de los incisos presentes en la ley $n^{\circ} 12.305$, junto con la mayor inversión en la creación de oficinas de concientización de la población puede ayudar en la evolución de los sistemas de gestión de los municipios de la microrregión estudiada.

Keywords: Política nacional. Gestión. Colecta Selectiva. Concienciación.

Abstract- Waste management is a sector of public sanitation, which originated in the colonial period. Currently, however, the management of these wastes is a complex issue due to the high urban expansion, the large amount and diversity of waste produced, limited public resources and limitations of energy and natural resources. The aim of this study was to investigate the current situation of solid waste management in Lavras' microregion. Thus, the study was conducted using data obtained through visits to municipalities, consulting official information from national and state database such as IBGE and Fundação Estadual do Meio Ambiente. Based on these data, it was concluded that the Lavras' microregion, integrated solid waste management is still evolving, once that most part of its municipalities still does an irregular final destination of the solid waste in lanfill, need to support recycling and waste pickers and feature non-conformities with the Law No. 12.305, which rules the National Solid Waste Policy. A more effective government action by requiring compliance with the items present in Law No. 12,305 and greater investment in creating awareness workshops of the population can help in the evolution of the management systems in the studied micro-region's municipalities.

Keywords: National policy. Management. Selective collection. Awareness.

\section{INTRODUÇÃO}

A gestão integrada de resíduos sólidos é constituída de ações voltadas para a busca de soluções para os resíduos gerados pelo homem, considerando as dimensões política, econômica, ambiental, cultural e social, com controle social e sob a premissa de desenvolvimento sustentável (BRASIL, 2010a). No entanto, atualmente, a gestão de resíduos é uma questão complexa devido à elevada expansão urbana, a grande quantidade e diversidade de resíduos produzidos, recursos públicos limitados, impacto da tecnologia e limitações de energia e recursos naturais (BRAGA; DIAS, 2008).

Em Minas Gerais, a dificuldade na gestão dos resíduos sólidos é intensificada pelo fato deste Estado ser o segundo maior produtor desses resíduos na região sudeste, depois de São Paulo (37.389 toneladas/dia), produzindo aproximadamente 13.365 toneladas/dia. A quantidade diária de resíduos domiciliares, 3.64 toneladas/dia, é maior do que a encontrada em vias e logradouros públicos, 1.555 toneladas/dia (IBGE, 2010a). Diante dessa grande quantidade de resíduos produzida, é necessário que se tenha conhecimento de como esta produção vem sendo tratada em cada região e suas microrregiões, possibilitando a procura por uma gestão eficiente desses resíduos.

Na microrregião de Lavras, no sul do Estado de Minas Gerais, até o presente momento, não havia nenhum estudo que tenha feito um levantamento acerca de como são geridos os seus resíduos. Assim, este estudo tem como objetivo verificar através de um levantamento de dados a atual situação da gestão de resíduos sólidos nos municípios da microrregião de Lavras, discorrendo sobre suas formas de gestão e a adequação das mesmas às normas federais (BRASIL, 2010a) e possíveis ferramentas que auxiliem num bom funcionamento de tal gestão nesses municípios. Com as informações aqui expostas, espera-se não apenas atentar a esfera do poder público, mas também contribuir com informações que chamem atenção da comunidade científica para maiores empreendimentos de pesquisas na microrregião em questão, como também em outras regiões do Estado de Minas Gerais que não tenham levantamento de sua situação atual quanto ao seu manejo de resíduos sólidos. 


\section{REVISÃO DE LITERATURA}

A gestão de resíduos sólidos é um conjunto de ações associadas ao controle da geração, armazenamento, coleta e transporte, processamento e disposição final desses resíduos, sempre respeitando os princípios da saúde pública, economia, engenharia e conservação de recursos naturais, proporcionando também as mudanças de hábitos da comunidade (BRAGA; DIAS, 2008). O gerenciamento de resíduos sólidos, um setor do saneamento público, teve origem no período imperial (1880), no Rio de Janeiro pelo decreto 3024 de Dom Pedro II, e por muito tempo não recebeu a merecida atenção do público (MONTEIRO et al., 2001).

A produção de resíduos sólidos pode ter diversas origens, sendo: os resíduos domiciliares, resíduos provenientes da limpeza urbana, resíduos de estabelecimentos comerciais e prestadores de serviços, resíduos dos serviços públicos de saneamento básico, resíduos industriais, resíduos de serviços de saúde, resíduos da construção civil, resíduos agrossilvopastoris, resíduos de serviços de transporte e resíduos de mineração (BRASIL, 2010a).

Os resíduos sólidos ainda podem ser divididos em duas classes, de acordo com os riscos que podem ou não representar ao meio ambiente e a saúde pública, que são as classes dos perigosos e não perigosos. A classe dos perigosos, diz respeito aos que por sua natureza inflamável, corrosiva, tóxica ou patogênica, como pilhas, baterias e lâmpadas fluorescentes, provocam riscos a saúde (ABNT, 2004; BRASIL, 2010a). Já a classes dos resíduos não perigosos, se subdivide em inertes e não inertes, sendo que os não inertes são aqueles que por suas naturezas de combustibilidade, solubilidade ou biodegradabilidade, podem representar riscos ao meio ambiente e a saúde pública (não entram na classe dos perigosos e nem a dos inertes) (ABNT, 2004).

Com relação aos resíduos inertes, esses teoricamente não representam riscos à saúde e ao meio ambiente, como os pneus (ABNT, 2004). Entretanto, resíduos como os pneus se deixados em ambiente aberto, sujeito a chuvas, acumulam água, favorecendo a proliferação de mosquitos, e em unidades de incineração, a queima da borracha gera enormes quantidades de material particulado e gases tóxicos, necessitando de um sistema de tratamento dos gases extremamente eficiente e caro (MONTEIRO et al., 2001). Dessa maneira, os resíduos sólidos devem ser gerenciados de acordo com suas características, sobretudo, os resíduos especiais como os produzidos por serviços de saúde, que representam um risco potencial de doenças infectocontagiosas para a população, e os resíduos que podem ser reciclados ou reaproveitados. No caso dos resíduos orgânicos, há a possibilidade de serem aproveitados por meio da compostagem e serem utilizados como fertilizantes naturais.

De acordo com a Lei no 12.305, de agosto de 2010, referente à Política Nacional de Resíduos Sólidos, a destinação de resíduos inclui a reutilização, a reciclagem, a compostagem, a recuperação e o aproveitamento energético ou outras destinações admitidas pelos órgãos competentes do Sisnama, do SNVS e do Suasa, de modo a evitar danos ou riscos à saúde pública e à segurança e a minimizar os impactos ambientais adversos. A disposição final dos rejeitos deve ser distribuída de forma ordenada em aterros sanitários, observando normas operacionais específicas. (BRASIL, 2010a).

Há quatro formas que são utilizadas para a disposição final dos resíduos: lixão, aterro controlado, aterro sanitário e usina de triagem e compostagem (UTC). O lixão constitui uma forma inadequada para dispor os resíduos sólidos de um município, pois nele apenas são descarregados os resíduos em uma determinada área, sem qualquer manejo para proteção ao meio ambiente e saúde pública (FEAM, 2014). A presença de catadores em busca de materiais recicláveis ou reaproveitáveis próximos aos lixões deixa-os propensos a adquirirem doenças diversas, mediante o contato com substâncias contaminantes percoladas no solo e dispersas no ar (MONTEIRO et al., 2001; VIMIEIRO; PEREIRA; LANGE, 2009), oriundas, sobretudo, de resíduos orgânicos, transmitindo doenças infectocontagiosas à comunidade em que residem (MONTEIRO et al., 2001; CUSSIOL et al., 2009). No rancking dos problemas 
de saúde mais comuns causados pelo contato com lixões estão problemas gastrointestinais, irritação de pele, olhos e mucosas, e doenças pulmonares, devido à grande exposição a bactérias e esporos de fungos (MARTH et al., 1997).

$\mathrm{O}$ aterro controlado, embora não seja ainda a forma correta de disposição final, é uma forma que foi criada para minimizar os efeitos diretos dos resíduos dispostos a céu aberto como no lixão (MONTEIRO et al., 2001; FEAM, 2014). Para formar este tipo de aterro é destinada uma área adjacente a um lixão, na qual é feita a cobertura diária da pilha de lixo com terra ou outro material disponível como forração ou saibro. É feita uma barreira para proibir a entrada de pessoas estranhas e animais (FEAM, 2014). Este tipo de aterro seria uma situação intermediária entre o lixão e aterro sanitário, porém, é também ineficiente na mitigação dos impactos ambientais relacionados à contaminação de águas subterrâneas (MONTEIRO et al., 2001; FREIRE, 2009). Em concordância com o conceito proposto por Freire (2009), o termo Aterro Controlado é errôneo, sendo que leva ao incorreto entendimento de que a disposição de resíduos sólidos urbanos é feita em um aterro propriamente dito, e por isso o termo Lixão Controlado seria mais plausível ao ser empregado.

A forma adequada de disposição final, o aterro sanitário, se constitui da preparação do terreno a ser impermeabilizado, como o nivelamento e o selamento da base com argila ou mantas de PVC ou PEAD (Polietileno de Alta Densidade), para garantir que o lençol freático não seja contaminado, implantação de sistemas para captação e armazenamento ou queima do gás metano, oriundo da matéria orgânica decomposta (MONTEIRO et al., 2001). Simultaneamente são implantados sistemas de drenagem de gases e para o tratamento do chorume gerado. Neste aterro também ocorre a cobertura diária dos resíduos para evitar danos ou riscos a saúde pública e ao meio ambiente, mau cheiro e poluição visual. $A$ atuação de catadores também é proibida nesses aterros e há um controle da quantidade de resíduos inserida. Outro aspecto importante com relação aos aterros sanitários é que ao fim de sua vida útil, a empresa que o opera deve recuperar o terreno, incluindo neste aspecto a recomposição da paisagem (FREIRE, 2009; MONTEIRO et al., 2001; FEAM, 2014).

Na UTC, a forma de tratamento dos resíduos sólidos é considerada adequada. Essas UTCs são os equipamentos utilizados para separar materiais que podem ser reciclados, a matéria orgânica e os rejeitos. Neste aspecto, os materiais recicláveis, depois de separados, são prensados, enfardados e armazenados para posterior comercialização (MONTEIRO et al., 2001; FEAM, 2014). No caso da matéria orgânica, essa é tratada por um processo de compostagem, que é um método de conversão biológica da matéria orgânica, tendo como produto final o composto orgânico, um material rico em húmus e nutrientes minerais que pode ser, dentre várias aplicações, utilizado em paisagismos e na recuperação de áreas degradadas (FEAM, 2014).

Com relação à reciclagem, ainda há a necessidade de organização de mais cooperativas ou associações de catadores, para que as pessoas que se ocupem do trabalho da catação sejam mais capacitados e mantidos sob educação continuada para o serviço que vão realizar, recebendo equipamentos de proteção individual e instruções de como usá-los, além de receber assistência médica preventiva (CUSSIOL et al., 2006). Não menos importante, os catadores também devem ser esclarecidos sobre a sua contribuição para a sociedade, estimulando sua satisfação pessoal, e consequentemente a melhor produção (VIMIEIRO; PEREIRA; LANGE, 2009).

No gerenciamento dos resíduos sólidos urbanos, a entidade que faz coleta dos resíduos pode ser pública, como a prefeitura de um município, uma entidade privada, contratada pelo município ou até uma parceria da prefeitura com uma entidade privada, ou até mesmo um consórcio entre municípios (MONTEIRO et al., 2001). Na Região Sudeste, Minas Gerais não somente é o Estado com maior número de municípios, como também o que apresenta mais municípios nos quais a prefeitura é a única executora dos serviços de coleta (Tabela 1).

Nos últimos anos vários municípios brasileiros vêm abrindo mão da administração direta pelo governo municipal, para contratar parte dos serviços de limpeza urbana por empresas privadas, como uma forma 
de obter maior eficiência e agilidade administrativa, ficando por conta das funções de planejamento, coordenação e fiscalização, isto é, o gerenciamento de resíduos (MONTEIRO; MANSUR, 1991). Esta questão da privatização dos serviços de saneamento, entretanto, é controversa, devido a sua execução nem sempre ser satisfatória. Oliveira et al. (2011) comentam para o município de Cachoeiro do Itapemirim (ES) que os bairros mais carentes eram mal atendidos pelos serviços prestados pela empresa terceirizada, e o atendimento preferencial ocorria em áreas com maior desenvolvimento econômico.

$\mathrm{Na}$ área do saneamento básico que cuida dos resíduos, o investimento para sua execução eficaz ainda necessita de maior atenção do poder administrativo dos municípios, visto que o número de municípios com uma frequência de coleta de resíduos sólidos de até três vezes por semana realizada nos bairros é inferior a um terço da quantidade de municípios existentes em Minas Gerais (IBGE, 2010a). A coleta com frequência de até três vezes por semana nos centros dos municípios é ainda menor, e abrange 126 municípios no estado (IBGE, 2010a).

Tabela 1: Total de municípios dos quatro Estados da Região Sudeste com serviço de manejo de resíduos sólidos, por forma de execução dos serviços.

\begin{tabular}{|c|c|c|c|c|c|}
\hline \multirow[t]{2}{*}{ Região sudeste } & \multicolumn{5}{|c|}{ Municípios } \\
\hline & Total & Total & \multicolumn{3}{|c|}{ Forma de execução do serviço } \\
\hline Minas Gerais & 853 & 853 & 553 & 29 & 271 \\
\hline Rio de Janeiro & 92 & 91 & 61 & 16 & 14 \\
\hline São Paulo & 645 & 645 & 312 & 88 & 245 \\
\hline
\end{tabular}

Fonte: IBGE (2010a)

Além da atenção requerida por parte do poder público, as populações também devem se atentar aos seus níveis de consumo, de forma a minimizar a quantidade de resíduos gerada. Para que esta consciência seja despertada nos cidadãos, uma forma seria a realização de oficinas em bairros nos munícipios, coordenadas pelas prefeituras, visando lhes mostrar as problemáticas geradas pela alta quantidade de resíduos gerados e como podem colaborar para o quadro ser revertido.

A normatização federal estabelecida pela Lei no 12.305 também se mostra uma forma promissora na regularização do gerenciamento de resíduos sólidos, pois ela trata dos aspectos gerais envolvendo tanto resíduos urbanos quanto rurais. Neste aspecto, também é necessária uma pesquisa que mostre como os municípios da microrregião de Lavras estão aderindo à lei e discuta a sua aplicabilidade perante a postura de grande parte da sociedade quanto à produção excessiva de resíduos.

\section{MATERIAIS E MÉTODOS}

\subsection{Descrição da localidade de estudo}

O município de Lavras é localizado na mesoregião do Campo das Vertentes, no Sul do Estado de Minas Gerais, a uma latitude $21^{\circ} 14^{\prime} 30$ sul e a uma longitude $44^{\circ} 00^{\prime} 10$ oeste, estando a uma altitude de 919 metros e possuindo uma área de 564,5 km². As cidades que compõe a microrregião de Lavras (figura 1) são Carrancas, Ingaí, ljaci, Itumirim, Itutinga, Lavras, Luminárias, Nepomuceno e Ribeirão Vermelho (SIDRA, 2016). A tabela 2 exibe os dados geoeconômicos dos municípios. 


\section{ANAP Brasil V. 10, n. 18}

Figura 1: Mapa da Microrregião de Lavras, e a localização da microrregião no Estado de Minas Gerais.

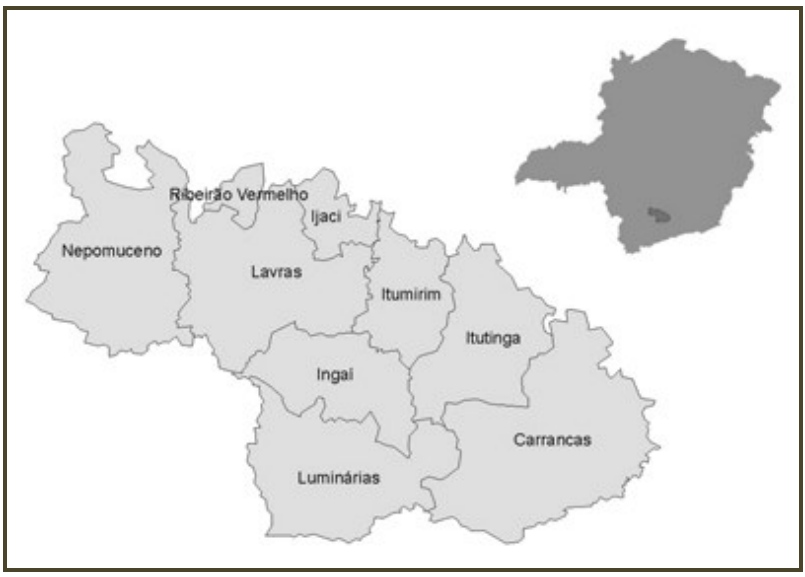

Fonte: Os autores

Tabela 2: Dados geográficos dos nove municípios da microrregião de Lavras-MG.

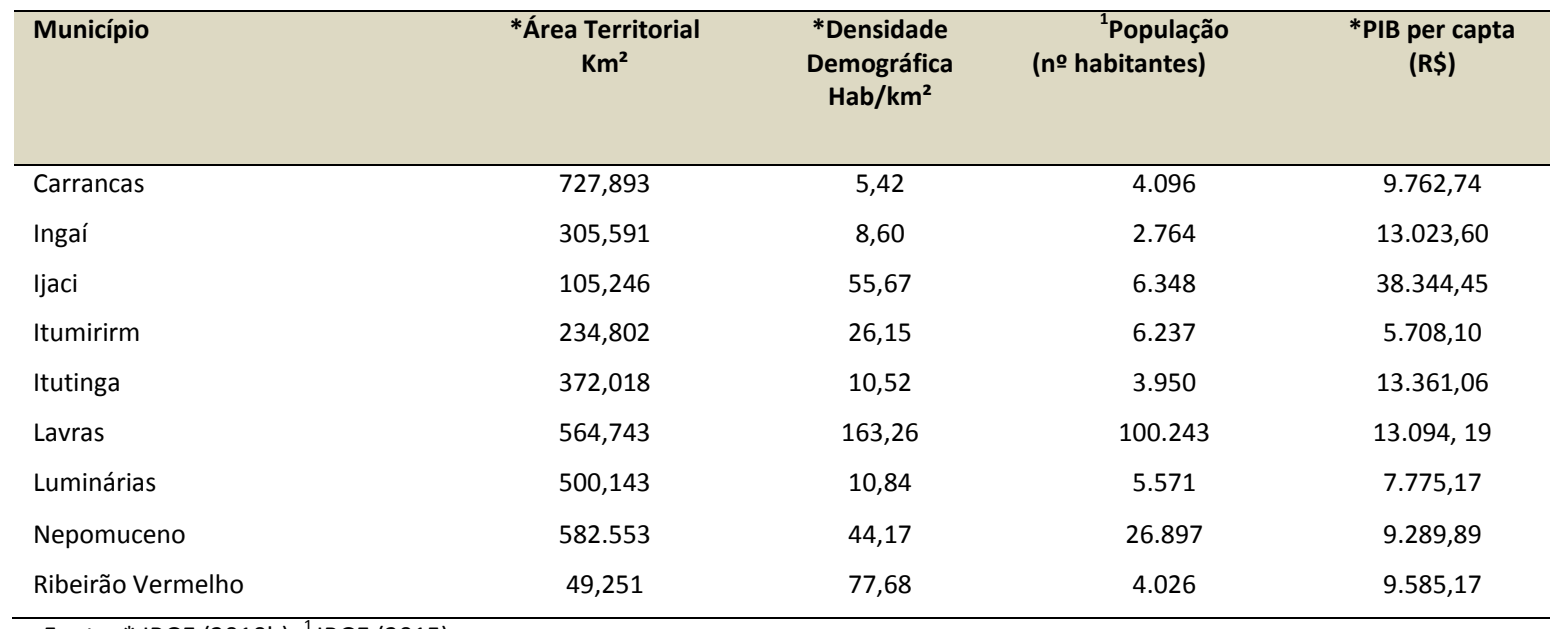

Fonte: * IBGE (2010b); ${ }^{1}$ IBGE (2015).

Conforme pode ser observado na Tabela 2, alguns municípios que constituem a microrregião de Lavras, apesar de possuírem uma pequena população possuem grande área territorial, e neste caso, Carrancas e Luminárias possuem uma área maior que a de Lavras, podendo essa diferença em dimensão território também influenciar na quantidade de resíduos depositada em suas áreas.

\subsection{Coleta e organização das informações}

A coleta de informações acerca da gestão de resíduos sólidos nos municípios alvos do estudo seguiu ordenadamente os seguintes passos:

a) Primeiro foi feita uma busca geral no Google com as palavras-chave: "Gestão resíduos sólidos"; Gestão resíduos sólidos Brasil", "Gestão resíduos sólidos Minas Gerais" e a primeira palavrachave empregada seguida do nome de cada cidade da microrregião de estudo. Após esta pesquisa inicial, a qual nos auxiliou também a obter informações para compor nossa 
introdução, revisão de literatura e discussão, utilizamos as mesmas palavras-chave direcionadas à sites de bancos nacionais de dados com as informações mais atuais possíveis no contexto deste estudo como o do Instituto Brasileiro de Geografia e Estatística (link principal utilizado em IBGE (2010a)), FUNDAÇÃO ESTADUAL DO MEIO AMBIENTE (link principal utilizado em FEAM (2012)), SISTEMA NACIONAL DE INFORMAÇÕES SOBRE O SANEAMENTO (link principal utilizado em SNIS (2013)).

b) Com os dados obtidos através do passo 1, nós organizamos as informações obtidas em tabelas com informações específicas sobre os municípios da microrregião. A seleção das informações julgadas mais importantes para descrever a microrregião quanto as formas de gestão de resíduos sólidos seguiu os pontos elencados como fundamentais para tal levantamento de dados proposto por Monteiro et al. (2001) e principalmente a normativa federal estabelecida por Brasil (2010a). Assim, as informações julgadas básicas e cruciais que foram inseridas no levantamento foram: o tipo de gestão empregada, entidade que realiza o gerenciamento dos resíduos, quantidade de municípios com presença ou ausência de coleta seletiva, cooperativas organizadas e credenciadas de catadores.

c) Foram feitas visitas aos municípios-alvo na segunda e quarta semana do mês de Março de 2016, visto a viabilidade de serem próximos uns dos outros. Em cada município, recorremos a funcionários públicos do setor de saneamento das prefeituras para nos esclarecer como os resíduos sólidos são gerenciados, bem como também nos conduzir aos locais de destinação final desses resíduos. Tais visitas aos locais de destinação final apenas não foram possíveis nos municípios de Carrancas e Nepomuceno. Esta etapa foi conduzida, objetivando verificar quais dos municípios ainda se encaixam nas classificações de gestão de resíduos encontrada em FEAM (2012) e estão ou não em conformidade com a Lei no 12.305 (BRASIL, 2010a).

d) Foi utilizado o programa ArcMap versão 10.3.1, aplicativo do software ArcGis para a construção do mapa da Figura 1.

\section{RESULTADOS E DISCUSSÃO}

As informações obtidas acerca da gestão de resíduos sólidos na microrregião de Lavras estão disponibilizadas no levantamento conduzido por FEAM (2012) estão dispostas na Tabela 3. De acordo com as informações obtidas diretamente nos municípios há situações contrárias na gestão de resíduos sólidos dos municípios de ljaci e Ribeirão Vermelho (agora com Aterro Controlado); Itumirim e Luminárias (agora com lixão). Portanto, dentre os nove munícipios dois regrediram em sua forma de gestão dos resíduos sólidos, voltando ao uso de lixão a céu aberto; dois passaram do lixão para aterro controlado (uma "evolução moderada") e os demais permaneceram com a mesma forma de gestão (Carrancas, Ingaí, Itutinga, Lavras e Nepomuceno; Tabela 3).

Tabela 3: Local utilizado para disposição de resíduos sólidos e presença de coleta seletiva nos municípios da Microrregião de Lavras, Minas Gerais.

\begin{tabular}{|c|c|c|}
\hline Municípios & $\begin{array}{c}\text { Local de disposição de } \\
\text { Resíduos sólidos }\end{array}$ & Coleta seletiva \\
\hline Carrancas & UTC & Presente \\
\hline Ingaí & Aterro controlado & Ausente \\
\hline ljaci & Lixão & Presente \\
\hline Itumirim & Aterro controlado & Ausente \\
\hline Itutinga & Aterro controlado & Presente \\
\hline Lavras & Lixão & Presente \\
\hline Luminárias & Aterro controlado & Ausente \\
\hline Nepomuceno & Lixão & Presente \\
\hline Ribeirão Vermelho & Lixão & Presente \\
\hline
\end{tabular}


A disposição final dos resíduos sólidos nos municípios da microrregião, com exceção de Carrancas, se mostrou inadequada, sendo feita em lixões e aterros controlados. Tal forma de disposição foge das exigências declaradas por normativa federal (BRASIL, 2010a) e demais normas técnicas (MONTEIRO et al., 2001; ABNT, 2004; FEAM, 2014), que visam o correto tratamento dos resíduos.

Em todos os municípios da microrregião, a prefeitura é responsável pelo gerenciamento dos resíduos. As informações do Programa Minas Sem Lixões da Fundação Estadual do Meio Ambiente (FEAM, 2012) mostram que dentre os municípios da microrregião, apenas o município de Carrancas trata os seus resíduos sólidos através do emprego de uma usina de triagem e compostagem regularizada (UTC). Entretanto, mesmo que não conste nos dados da FEAM (2012), no munícipio de Lavras há a Associação de Catadores de Materiais Recicláveis (ACAMAR), que também não aparece cadastrada nos dados recentes do Sistema Nacional de Informações Sobre o Saneamento, com ano base em 2011 (SNIS, 2013). Além disso, outros municípios com coleta seletiva (Tabela 3), a recebem através da atuação informal de catadores que juntam o material reciclável para venda em locais de Lavras que compram resíduos oriundos de papel, litro descartável e metal. Assim, não há uma organização, com exceção de Lavras e Carrancas, de cooperativas que regulamentem e apoiem a atuação dos catadores.

Para um município ou mesmo uma região ter um bom Índice de Desenvolvimento Humano (IDH), é necessário que todas as localidades tenham atendimento igualitário do serviço de limpeza pública. Além da microrregião, o Sul do Estado de forma geral mostra que apenas $31,7 \%$ da população urbana é atendida por tipologias de destinação de resíduos dentro das conformidades estabelecidas na Lei no 12.305 (BRASIL, 2010a), sendo repartidas em 19,7\% de atendimento por meio de aterros sanitários e 6,7\% por UTCS (FEAM, 2014).

As unidades apropriadas para a disposição dos resíduos sólidos é, juntamente com o excesso de resíduos produzidos e o não reaproveitamento um dos sérios problemas que precisam ser encarados. $\mathrm{E}$ esta situação não se restringe a microrregião de Lavras, visto que de acordo com FEAM (2012), 35,9\% da população no sul de Minas Gerais ainda fazem a disposição dos resíduos em lixões. A disposição em aterros controlados também ainda é alta, 28,7\%.

Em suma, foi constatado que a gestão de resíduos sólidos na microrregião de Lavras não somente está em desacordo com a proteção ao meio ambiente e a saúde pública, como também o está com a Lei no 12.305 (BRASIL, 2010a). Com as exigências propostas pela referida lei é esperado que tal situação seja melhor revertida, visto que um de seus princípios institui que o protetor, ou seja, aquele que gerencia corretamente os resíduos recebe apoio e benefícios do governo, e aquele que polui deve pagar por sua negligência.

A lei proíbe lixões a céu aberto e aterros controlados, e as administrações públicas municipais devem construir aterros sanitários no prazo máximo de quatro anos (mês/ano base é ago/2010), para depósito de resíduos com possibilidade de reciclagem e reaproveitamento, sendo obrigatória a compostagem de resíduos orgânicos. Os fabricantes, distribuidores e comerciantes, organizados em acordos setoriais, ficam obrigados a recolher e destinar para a reciclagem as embalagens de plástico, papel, papelão, de vidro e as metálicas usadas. Setores da construção civil e agricultura são proibidos de encaminhar seus resíduos para os aterros. De maneira que garanta o cumprimento dessas exigências, a lei ainda obriga as administrações públicas municipais e instituições a apresentar, no prazo de dois anos, um Plano de Gestão de Resíduos. Do contrário, não receberão recursos de fontes federais, destinados ao gerenciamento de resíduos, inclusive empréstimos.

No que se refere à reciclagem, de acordo com o artigo 36 da Lei no 12.305, as cooperativas de catadores terão prioridade na coleta seletiva, sendo dispensada a licitação, o que permite proporcionar melhor condição de trabalho aos ocupados com o serviço de catação, e aumento do aproveitamento de matéria-prima. Segundo o artigo 32, deve haver melhor aproveitamento da matéria-prima pós-consumo e fabricação de embalagens reutilizáveis, o que pode não somente impulsionar as ações de reciclagem, 
e consequentemente, um incremento na economia. O monitoramento das diversas atividades relacionadas à gestão de resíduos sólidos se faz necessário para aplicação efetiva da Política Nacional de Resíduos Sólidos. Mas, essa eficácia só pode ser melhor alcançada se o conhecimento de causa sobre a gestão de resíduos for levado à comunidade, para que a mesma também possa ter consciência e participar da tomada de decisões do que representa para si mesma uma melhor qualidade de vida.

\section{CONCLUSÃO}

A gestão de resíduos sólidos ainda é um sério problema na microrregião de Lavras, visto que a maioria dos municípios ainda gerencia irregularmente a destinação e tratamento de seus resíduos sólidos, fazendo uso de lixão a céu aberto. Além disso, também há ainda pouco apoio a atuação de catadores de materiais recicláveis por meio da organização de cooperativas. Uma atuação mais incisiva do setor governamental através do monitoramento das gestões de acordo com a Lei no 12.305 , como também mais investimento em oficinas de conscientização para população, pode se mostrar eficiente em auxiliar o avanço da gestão de resíduos sólidos.

\section{REFERÊNCIAS BIBLIOGRÁFICAS}

ASSOCIAÇÃO BRASILEIRA DE NORMAS TÉCNICAS (ABNT). Resíduos sólidos- classificação: NBR 10004. Rio de Janeiro: ABNT, 2004.

BRAGA, M.C.B.; DIAS, N.C. Gestão de resíduos sólidos urbanos: Volume I. Curitiba: [s.n.], 2008.

BRASIL. Lei no 12.305, de 02 agosto de 2010. Política nacional de resíduos sólidos. Câmara dos Deputados, Centro de Documentação e Informação (CEDI), Brasília, DF, 2010a. Disponível em:

<http://www.planalto.gov.br/ccivil_03/_ato2007-2010/2010/lei/l12305.htm> Acesso em: 27 fev. 2016.

CUSSIOL, N.A.M.; ROCHA, G.H.T.; LANGE, L.C. Quantificação dos resíduos potencialmente infectantes presentes nos resíduos sólidos urbanos da regional sul de Belo Horizonte, Minas Gerais, Brasil. Caderno da Saúde Pública, Rio de Janeiro, v.22, n.6, p.1183-1191, 2006.

FREIRE, G.J.M. Análise de Municípios Mineiros quanto à Situação de seus Lixões. 2009. 104p. Belo Horizonte, MG. Dissertação (mestrado em Análise e Modelagem de Sistemas Ambientais), Universidade Federal de Minas Gerais, Belo Horizonte, 2009.

FUNDAÇÃO ESTADUAL DO MEIO AMBIENTE (FEAM). Classificação e Panorama da Destinação dos Resíduos Sólidos Urbanos em Minas Gerais-Ano Base 2012. Belo Horizonte: Fundação Estadual do Meio Ambiente, 2012. Disponível em:<http://www.feam.br/images/stories/minas_sem_lixoes/2013/novo/classificao_e_panorama_2012.pdf > Acesso em: 01 fev. 2016.

. Panorama da destinação dos resíduos sólidos urbanos no Estado de Minas Gerais em 2012. Belo Horizonte: Fundação Estadual do Meio Ambiente, 2014.

INSTITUTO BRASILEIRO DE GEOGRAFIA E ESTATÍSTICA (IBGE). Pesquisa nacional de saneamento básico 2008. Rio de Janeiro: IBGE, 2010a. Disponível em:

<http://www.ibge.gov.br/estadosat/temas.php?sigla=mg\&tema=saneamentobasico2008> Acesso em: 14 fev. 2016.

. Censo Demográfico 2010. Rio de Janeiro: IBGE, $2010 \mathrm{~b}$.

. Estimativas da população residente nos municípios brasileiros com data de referência em 1으 de Julho de 2015. Rio de Janeiro: IBGE, 2015. Disponível em: < 


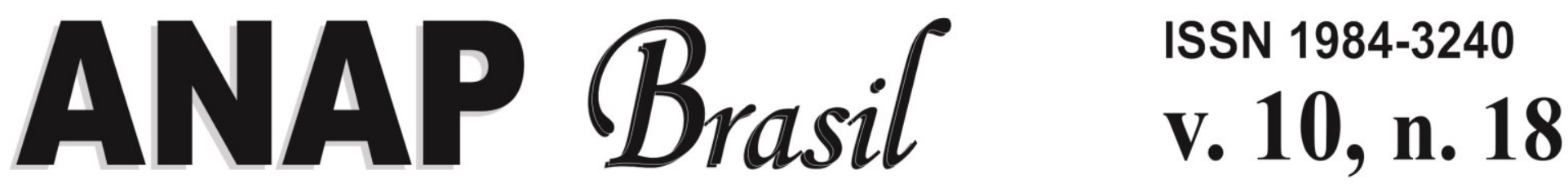

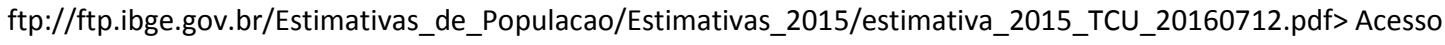
em: 01 fev. 2016.

MARTH, E. et al. Occupational health risks to employees of waste treatment facilities. Annals of Agricultural and Environmental Medicine, v.4, p.143-147, 1997.

MONTEIRO, J.H.P. et al. Manual gerenciamento integrado de resíduos sólidos. Rio de Janeiro: SEDU/IBAM, 2001.

MONTEIRO, J.H.R.P.; MANSUR, G.L. Cartilha de Limpeza Urbana. Rio de Janeiro: CPU/IBAM e SNS/MAS, 1991.

Disponível em:

OLIVEIRA, T.G.; REZENDE, S.; HELLER, L. Privatização dos serviços de saneamento: uma análise qualitativa à luz do caso de Cachoeiro de Itapemirim (ES). Engenharia Sanitária e Ambiental, Rio de Janeiro, v.16, n.4, p. 395-402, 2011.

SISTEMA IBGE DE RECUPERAÇÃO AUTOMÁTICA (SIDRA). Nível Territorial: Microrregião Geográfica. Instituto Brasileiro de Geografia e Estatística: Rio de Janeiro, 2016. Disponível em:

http://www.sidra.ibge.gov.br/bda/territorio/tabunitsub.asp?codunit=6309\&nsub=6\&z=t\&o=4\&i=P>Acesso em: 04 fev. 2016.

SISTEMA NACIONAL DE INFORMAÇÕES SOBRE O SANEAMENTO (SNIS). Diagnóstico do Manejo de Resíduos Sólidos - 2011: Tabelas de informações e indicadores, III Região Sudeste. Brasília: MCIDADES.SNSA, 2013. Disponível em: <http://www.snis.gov.br/PaginaCarrega.php?EWRErterterTERTer=91> Acesso em: 05 fev. 2016.

VIMIEIRO, G.V; PEREIRA, L.Z.; LANGE, L.C. Trabalho e qualidade de vida em usinas de triagem e compostagem de resíduos urbanos. Revista de Administração FACES Journal, Belo Horizonte, v.8, n.2, p.94-105, 2009. 